\title{
Juan Carlos Rodríguez y el drama burgués'
}

\author{
JESÚS RUBIO JIMÉNEZ \\ Universidad de Zaragoza \\ España \\ jrubio@unizar.es
}

(Recibido: I8-IO-2OI7; aceptado: 2O-IO-2OI7)

En 2010, cuando iniciamos la andadura de Álabe, Juan Carlos Rodríguez escribió el primer "Álabe imprescindible" en homenaje a José Saramago. Desde ese primer número el Maestro nos acompañó volumen a volumen, compartiendo su sabiduría y su humanidad, hasta el último momento. Hoy Jesús Rubio nos hace seguir teniéndolo presente, ahora como protagonista de este homenaje que para nosotros es especialmente sentido y necesario. En aquel texto sobre Saramago Rodríguez hablaba de que "no se trata de un pasar por la vida, se trata de un asentarse en ella y reflexionarla, practicarla". Y leerla, añadimos, y enseñarnos a leerla, como él hizo.

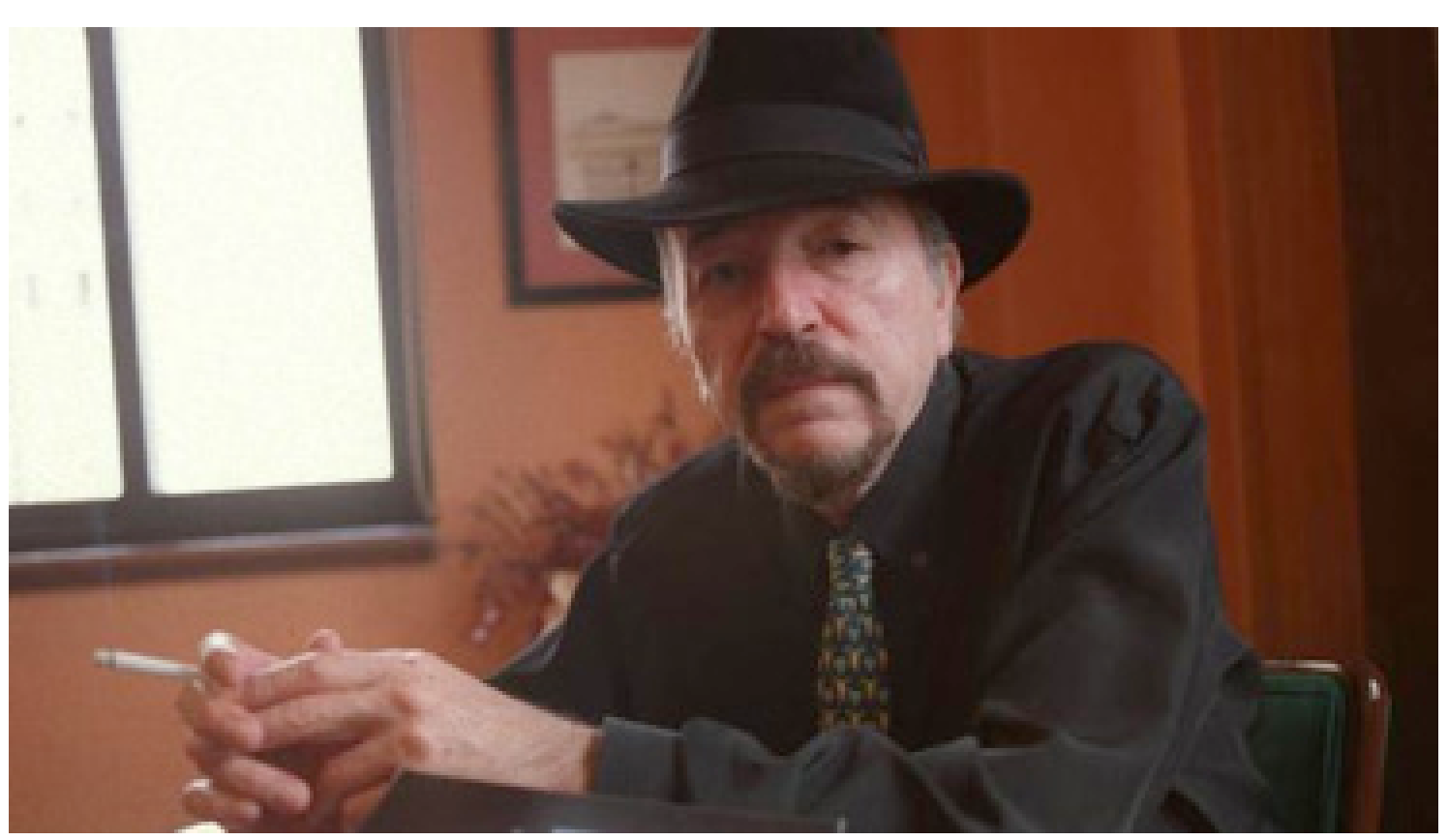

\footnotetext{
I Para citar este artículo: Rubio Jiménez, Jesús (2018). Juan Carlos Rodríguez y el drama burgués. Álabe 17. [www.revistaalabe.com] DOI: I0.I5645/Alabe20I8.I7.IO
} 
Después de visitar Granada a comienzos de los años veinte con su esposa Zenobia Camprubí, Juan Ramón Jiménez le escribió a Isabelita García Lorca²:

«Iremos todos los otoños a Granada a morirnos un poco, cada año, de esa vida verdadera, profunda, terrible, del sentimiento prisionero entre torres sin guarda, acompañada de montañas indecibles.»

Así vengo hoy yo a Granada en este recién estrenado otoño: a morirme un poco por la añoranza de esa vida verdadera y profunda que transmitía Juan Carlos en esta incomparable ciudad y en esta universidad.

La razón por la que he elegido el tema de «Juan Carlos Rodríguez y el drama burgués» para mi conferencia es doble:

I. Muchos escritos de Juan Carlos me han acompañado durante años, pero especialmente los que tratan sobre teatro, dado que una de mis dedicaciones ha sido el estudio del teatro español contemporáneo.

2. El teatro y su análisis fue uno de los temas de conversación recurrentes en nuestros encuentros de los últimos años. Generosamente, él se venía a mi terreno y así la conversación resultaba más fácil, lo cual no quiere decir que pasados unos minutos no estuviéramos ya muy lejos de tales temas. Algo así puede que ocurra en esta conferencia: comenzamos hablando del drama teatral burgués, pero será inevitable que derivemos hacia el drama de la cultura burguesa en general.

Aunque se le recuerda quizás más por otros trabajos o por su indudable magisterio sobre los poetas de la llamada «otra sentimentalidad», lo cierto es que la reflexión sobre el teatro ocupó un lugar destacado en los estudios de Juan Carlos Rodríguez. De hecho, la primera referencia que ofrece Juan Antonio Hernández García en su bibliografía, nada menos que de i96r, ya se refiere al arte escénico ${ }^{3}$. Era entonces un joven estudiante universitario y en sus colaboraciones en la revista Papeles universitarios, de Granada, ya se ocupaba del arte escénico al hilo de las funciones que ofrecían por entonces el TEU granadino: «Teatro. Preguntan por Julio César» (Papeles universitarios, I, marzo de i96I, p. 3). Siguieron otras reseñas de funciones de aquellos activos grupos estudiantiles.

Fue, sin embargo, en la segunda mitad de los años setenta cuando publicó sus dos trabajos fundamentales sobre el arte escénico:

El primero de ellos, «Escena árbitro / estado árbitro (Notas sobre el desarrollo del teatro desde el siglo XVIII a nuestros días)» en la obra colectiva El teatro y su crítica, editada en Málaga en el Instituto de Cultura de la Diputación Provincial, 1975, pp. 59IO7. Después recogido en La norma literaria desde su primera edición en I984.

\footnotetext{
3 Juan Antonio Hernández García, «Han pasado los años [I96I-20I3]. Una bibliografía de Juan Carlos Rodríguez», Youcali, ${ }_{5} 5$.

${ }^{2}$ Este ensayo corresponde al texto de la conferencia pronunciada en la Universidad de Granada el 28 de septiembre de 20I7, dentro del ciclo: Maestro y amigo. Jornadas en memoria de Juan Carlos Rodríguez. Se mantiene el texto tal como fue escrito.
} 
El segundo, «Algunas claves de lectura para el Diario de trabajo», Cuadernos de teatro, I, mayo de I979, pp. 23-48.

Iniciaba con ellos su reflexión teórica sobre el drama burgués y su devenir, tomando como punto de partida el teatro ilustrado y a Diderot en el primer caso y a Bertolt Brecht en el segundo. Eran, como tantos otros escritos suyos, «trabajos en marcha», provisionales, «materiales» para la reflexión, presentados el primero como «Notas» y el segundo como «Claves». Después siguió durante años volviendo sobre ellos y sobre sus múltiples implicaciones.

Un desarrollo del primer ensayo y referido al caso del drama burgués español puede considerarse su libro Moratín o el Arte Nuevo de Hacer Teatro. Con la edición facsímil de la Vida de Guillermo Shakespeare y la traducción de Hamlet de Leandro Fernández de Moratín (Granada, Caja General de Ahorros de Granada, I99I). También algunos otros trabajos que son hijuelas de su reflexión sobre el drama ilustrado, escritas como ponencias de algunos congresos: «La mirada distante: el nacimiento del teatro moderno» (Edad de Oro, XVI, I997, 277-295). Después recogido en De qué hablamos cuando hablamos de literatura, 2002, 57 ${ }^{\mathrm{I}}{ }^{-596}$. Su origen fue una ponencia para el congreso Edad de oro, al que lo invitó el profesor Pablo Jauralde. Y «La ilustración y la invención de la naturaleza humana (Moratín en el laberinto de las luces)», en Cuadernos de Ilustración y Romanticismo, I9, 20I3, 27-56. (Y en Tras la muerte del aura (En contra y a favor de la Ilustración), 2OII, pp. I37-2II). Fue una ponencia que yo mismo tuve el honor de encargarle para la conferencia de clausura del congreso sobre Ilustración y Modernidad escénica, que tuvo lugar en Cádiz en 2008.

El desarrollo más amplio de sus reflexiones sobre el Diario de trabajo de Bertolt Brecht fue «Brecht y el poder de la literatura», presentación del libro Brecht, siglo $X X$ (Comares, I999), que tiene también hijuelas como «De La Celestina a Madre Coraje: la mujer creada por el mercado» (I999). El primero fue recogido de De quéhablamos cuando hablamos de marxismo, $2 \mathrm{OI} 3$.

Diderot, Moratín hijo y Brecht fueron por decirlo así sus mentores en su reflexión sobre el arte escénico burgués. No son muchos, pero sí densos ensayos y que han tenido una difusión suficiente, con distintas ediciones, aunque sin la proyección que han tenido otros escritos suyos sobre la poesía o la narrativa. Pero esto ya forma parte de otro asunto, que es la presencia social de los distintos géneros literarios y su prestigio social. Y es evidente que el teatro no cuenta hoy con el prestigio ni la demanda social de la poesía o la novela, ni como asistencia a los espectáculos ni mucho menos como lectura.

Han pasado, además, más de 40 años desde que Juan Carlos formuló sus ideas sobre el drama burgués, lo cual obliga ya, para entenderlas adecuadamente, a un primer y breve acercamiento historiográfico para proceder después a considerar su posible vigencia.

«Escena árbitro / estado árbitro...» fue escrito para una reunión sobre El teatro y su crítica, dentro de una serie de Reuniones sobre los distintos géneros que tuvieron 
lugar en Málaga y en las que intervenían profesores de Literatura y cultivadores de los distintos géneros, en este caso dramaturgos ${ }^{4}$. Existen unas entregas similares sobre poesía y novela ${ }^{5}$. Eran años de renovación historiográfica y crítica y de aquella reunión malagueña fue el trabajo más rompedor. Se estaba saliendo de la autarquía franquista también en los métodos críticos de acercamiento a la literatura y en la elaboración de su historia.

En cuanto a «Algunas claves de lectura para el Diario de trabajo», debo decir que es una revista que no he tenido ocasión de ver, pero que hay que situar en el horizonte también renovador de aquellos primeros años de la transición en que se consideraba todavía el teatro brechtiano como uno de los modelos fundamentales del teatro comprometido, dirigido a la formación crítica de los espectadores más que a su mera diversión. Desarrollo natural de los desaparecidos TEUS desbordados por la nueva situación histórica. Tuvo este trabajo una difusión reducida y solo alcanzó todo su desarrollo incorporado y refundido en «Brecht y el poder de la literatura», amplio estudio - en realidad un libro en sí mismo- que introduce Brecht, siglo $X X$ (I999), uno de los varios libros con se conmemoró el centenario del dramaturgo.

La reflexión sobre el drama burgués de Juan Carlos por tanto se movió entre los ilustrados Diderot o Moratín y la representación de lo privado que caracteriza el moderno drama burgués y por otro lado, en torno a Brecht, que formuló desde su particular militancia marxista el llamado teatro épico, concebido como un medio de análisis de las contradicciones de la sociedad capitalista y el lugar del pensamiento crítico en ella.

Cuando Juan Carlos presentó sus primeras «Notas» sobre el drama burgués ilustrado se estaba procediendo a una revisión en profundidad de nuestro siglo XVIII que por diversas circunstancias había quedado orillado y lo hizo situando el teatro ilustrado español tanto en las coordenadas propias como en las europeas. Es un primer aspecto interesante de su proceder habitual en este y otros estudios: Juan Carlos se movía siempre en un territorio transfronterizo, europeo. Se trataba no de hacer historia erudita local sino de indagar en la trama que sostiene el tapiz, para entender los conflictos profundos que subyacen a lo anecdótico.

Su inmersión en el Diario de trabajo de Brecht fue ante todo una reflexión sobre el lugar y el papel del intelectual en la sociedad. Brecht, desde que se conoció a fondo en el sur de Europa tras sus grandes estrenos en el Berliner o en París en los años cincuenta, era una de las grandes referencias para los intelectuales comprometidos y su teatro épico un modelo.

\footnotetext{
${ }^{4}$ El teatro y su crítica, reunión de Málaga de 1973, Málaga Instituto de Cultura de la Diputación Provincial, I973. Ed. de Manuel Alvar con textos de Alvar, A. Berenguer, Herman Bonnin, Antonio Gallego Morell, Luciano Garcia Lorenzo, Guido Mancini, Francisco García Pavón, Pilar Palomo, Antonio Prieto, Cándido Pérez Gallego, Juan Carlos Rodríguez. Dramaturgos: Fernando Arrabal, José Martín Recuerda, José María Rodríguez Méndez, Elena Romero.

5 Novela y novelistas. Reunión de Málaga de 1972, Diputación Provincial de Málaga, 1973. Y Poesía, reunión de Málaga de 1974, Diputación de Málaga, i976, 2 vols. Ed. de Manuel Alvar.

Similares encuentros en otros lugares como Prosa novelesca actual, Santander, UIMP, I969. Ed. Francisco Yndurain.
} 
Es decir, Juan Carlos al escribir sobre teatro seguía -como no podía ser de otro modo- las premisas básicas de su manera de entender la historia literaria que explicó bien en su último libro que debió haber sido el primero, nacido de su tesis doctoral defendida a comienzos de los años setenta en esta Universidad: Para una teoría de la literatura. Introducción al pensamiento crítico contemporáneo (I97I) ${ }^{6}$. Una tesis diferente a las que por entonces se presentaban en las universidades españolas.

Quedó inédita y en cierto modo arrinconada por sus libros: Teoría e historia de la producción ideológica: las primeras literaturas burguesas. Siglo XVI (1974), donde aplicaba al estudio de Garcilaso o Fray Luis de León conceptos críticos marxistas que había desarrollado en su tesis ante la sorpresa de los lectores de entonces habituados a lecturas nacidas del análisis estilístico dominante en los estudios literarios españoles. Después vinieron otras aplicaciones como La literatura del pobre (I994) sobre de la novela picaresca, considerada como una manifestación de las primeras literaturas burguesas, nacidas del paso del feudalismo al capitalismo. O El escritor que compró su propio libro. Para leer el Quijote (2003), presentando a Cervantes como un autor que escribe con conciencia del mercado, con temor a inventar la novela, atrapado en una realidad oscilante. Andaba también estos últimos años embarcado en una personal lectura de Góngora, cuya culminación algunos esperábamos con gran interés.

La visión de los poetas y narradores renacentistas como hombres de un tiempo nuevo, el de la burguesía, chocaba con lo establecido por la crítica hasta entonces y en su interpretación de la novela picaresca o del Quijote recalcaba la aparición de la mirada literal del mundo, incorporando en los textos la vida cotidiana y haciendo que estos se distanciaran cada vez más de visiones alegóricas anteriores.

Para algunos bienpensantes la llegada de Juan Carlos a los estudios literarios españoles fue la irrupción de un bárbaro que desbarataba esquemas escolásticos y estilísticos que se daban por inamovibles. Un término fantasmal movido por aires internacionales recorría y avalaba sus escritos: «marxista». Se trataba nada menos que de crítica «marxista» aplicada a Garcilaso, al Lazarillo, a Cervantes o a ¡Fray Luis de León!

Una vez catalogado el nuevo crítico no se entraba en mayores precisiones. ¿Para qué? Se estaba más cómodo al amparo de la contrastada escuela estilística española en muchos casos convertida en mero recuento aséptico de figuras retóricas, sin la sabiduría con que la ejercían Karl Vossler o Dámaso Alonso, que eran ante todo finos lectores, que es al cabo lo fundamental como señaló para el propio Juan Carlos Rodríguez el profesor Andrés Soria Olmedo con justeza en su necrológica publicada en Ínsula . No pocos pensaron que la manera de acercarse nuestra historia literaria propuesta por Juan Carlos Rodríguez pasaría como una nube de verano. Pero no solo no pasó, sino que cuarenta años después, el mismo fantasma volvió con muchos más aires internacionales y aquella tesis insólita mantenida en pie contra viento y marea se publicó en 2015 coincidiendo con la

\footnotetext{
${ }^{6}$ Juan Carlos Rodríguez (20i6). Para una teoría de la literatura (4o años de Historia). Madrid: Marcial Pons.

${ }^{7}$ Andrés Soria Olmedo, «Juan Carlos Rodríguez: un maestro de la lectura», Ínsula, 84O, 20I6, pp. 37-38.
} 
jubilación de su autor, como rúbrica de su brillante trayectoria académica y desarrollada y madurada durante cuatro décadas: Para una historia de la literatura (4o años de historia).

Medio siglo de fidelidad al marxismo, algo inconcebible para quienes se amueblan la cabeza con el último libro de moda y rinden sus armas al débil pensamiento posmoderno. Siempre anduvo en el telar de Juan Carlos Rodríguez este libro y gracias a eso hoy contamos con una brújula imprescindible para navegar por sus mares de tinta aminorando los riesgos de naufragar. Este libro es a la vez la columna vertebral de su pensamiento y una autobiografía intelectual.

Sostener planteamientos marxistas sonaba y suena a herejía en nuestro país. Se prefiere descalificar a estudiar y tratar de desentrañar el porqué de una elección de estas características y una fidelidad tan contrastada a lo largo y ancho de varios decenios. Ocurre sobre todo por prejuicios arrastrados -los viejos prejuicios contra lo nuevo que denunciaba alguien tan poco sospechoso de heterodoxia como el P. Feijóo- por los cuales se prefiere negar antes que ponerse a intentar entender lo propuesto, huyendo de simplificaciones y de mixtificaciones históricas que conducen a confundir lo que es un método nuevo de analizar la realidad con una militancia política ciega, comunista en este caso. Que marxismo y comunismo político tienen poco que ver queda históricamente muy claro en otro libro suyo que me ahorra entrar en detalles por este lado: De qué hablamos cuando hablamos de marxismo (2013).

En realidad, es fácil entender el porqué de su elección si se atiende a algunas ideas básicas que han guiado la peregrinación de Juan Carlos Rodríguez por la intrincada floresta de la literatura (y de la vida). La primera comparece inevitablemente en la página inicial del prólogo, la «radical historicidad de la literatura». No es muy diferente al arranque de Teoría e historia de la producción ideológica: las primeras literaturas burguesas, su primer libro, donde leemos: «los discursos a los que hoy aplicamos el nombre de literarios constituyen una realidad histórica que solo ha podido surgir a partir de una serie de condiciones - asimismo históricas- muy estrictas: las condiciones derivadas del nivel ideológico característico de las formulaciones sociales "modernas" o burguesas en sentido general.»

Es decir, lo que llamamos literatura no ha existido siempre, sino que esta comenzó a existir históricamente cuando se produjo el paso del feudalismo al primer capitalismo en el Renacimiento ${ }^{8}$. La literatura es un efecto de la historia y de los individuos históricos. Basta de esencialismos. A partir de esta nueva situación y como manifestación del hombre nuevo moderno se han ido desarrollando las literaturas occidentales a cuyo estudio dedicó tanto esfuerzo Juan Carlos Rodríguez, situándose en la particular posición de «pensar desde la explotación», que suponía tomar partido desde el comienzo, evitando los espejismos del «pensar libre» creados por las burguesías capitalistas dentro

\footnotetext{
${ }^{8}$ Con título similar se ha publicado un cumplido homenaje con motivo de,su jubilación:,La literatura no ha existido siempre. Para Juan Carlos Rodríguez. Teoría, historia, invención, Miguel Angel García, Ángela Olalla y Andrés Soria Olmedo (eds.), Universidad de Granada, 20I5.
} 
de su proceso de legitimación histórica. Este posicionamiento supone una actitud crítica frente al pensamiento burgués, una búsqueda permanente de sus fisuras y contradicciones, huyendo del fácil espejismo consistente en creer que el pensamiento y el sujeto que lo elabora son libres. No, por nuestro nacimiento en el sistema capitalista todos somos capitalistas y nuestra hipotética libertad de pensamiento no solo no está garantizada, sino que hay que construirla y ganarla día a día. Una de las mayores trampas del capitalismo ha sido su capacidad de mostrarse como el resultado del ejercicio de la libertad individual, cuando su base real es la explotación de las vidas de los otros.

La manera de analizar la realidad propuesta por el marxismo - entendido este en toda su complejidad y con un desarrollo permanente gracias a una continua discusión de sus supuestos- le fue descubriendo a Juan Carlos Rodríguez los límites del pensamiento y del yo, sus muchas paradojas y su estricta dependencia de la historia. El marxismo, eso sí, no entendido como un conjunto de ideas cerradas, insisto, sino como un método de análisis de la realidad en constante revisión y de aquí que ya en su tesis doctoral, por ejemplo, algunos de quienes aparecían en los años setenta como modelos de crítica marxista fueran ya criticados por su simplismo marxista que consideraba ya fosilizado: Lukács, Della Volpe. Por el contrario, su pensamiento andaba muy pendiente de otros autores más abiertos y porosos como Brecht o Gramsci o, si se piensa en sus maestros universitarios, en Louis Althusser. Es decir, quienes encontraban serias dificultades para ser escuchados en los propios partidos comunistas.

Cuarenta años de exigente pensamiento desde la explotación le proporcionaron a Juan Carlos Rodríguez un método de análisis de la cultura burguesa tan personal como brillante, consciente siempre de que el yo es humo y de que todo ser humano está sostenido por su «inconsciente ideológico» dependiente del momento histórico en que vive. Nada ocurre fuera de la historia. El yo de cada uno está construido y reprimido por el capitalismo inevitable. De aquí la necesidad de conocer lo mejor posible los mecanismos del capitalismo y el propio «inconsciente ideológico» para valorarlos en su justa mediday a partir de ahí construir un posible pensamiento individual consciente de sus límites.

Cuando Juan Carlos Rodríguez se refería al «inconsciente ideológico» lo hacía al mundo interior de cada individuo, nacido en unas circunstancias históricas determinadas, portador de un inconsciente libidinal, que jugará un papel fundamental en sus comportamientos. Es decir, junto a Marx, situaba a Freud, cuyo pensamiento y sus consecuencias no han sido tan resaltados en sus escritos, pero que resulta igualmente fundamental ${ }^{9}$. Se piensa históricamente y siempre desde dentro de la propia historia sin olvidar que la historia es una sucesión de diversas formas de explotación. De aquí la elección de su punto de vista: pensar desde la explotación, para mostrar sus mecanismos y denunciarlos. El análisis de la historia no se concluye nunca y el verdadero horizonte utópico es el de una

${ }^{9}$ En nuestra última conversación granadina, verano de 20I5, le animaba yo a volver sobre este asunto y a hacer más visible sus reflexiones freudianas. 
sociedad donde la norma básica y fundamental sea la libertad sin explotación. Nada está ganado definitivamente y solo un pensamiento en permanente alerta puede descubrir, describir y en caso necesario denunciar los mecanismos de explotación del capitalismo, que renueva permanentemente sus estrategias.

Para una teoría de la literatura ofrece entonces un balance del camino recorrido, pero no incidiendo tanto en lo personal - que no obstante está siempre subyacente- sino en como el capitalismo ha ido dando lugar a diferentes teorizaciones acerca de la literatura, cuyo repaso constituye el contenido del libro, buscando una presentación de sus conceptos medulares, para mejor conocer sus límites, que son los de quienes las elaboraron en sus circunstancias históricas con sus correspondientes débitos y contradicciones.

En este dominio es en mi opinión donde se descubre una de las peculiaridades más atractivas de la manera en que Juan Carlos Rodríguez elaboraba y exponía sus análisis. Sabía volar por las alturas filosóficas pero otras veces desciende a ras de tierra y la anécdota bien elegida o el análisis de obras concretas ilustran aquello que de otro modo quedaría reducido a un discurso abstracto y hasta abstruso. Juan Carlos Rodríguez siempre tejía su discurso con hilo de varias hebras: no falta nunca la fuerte hebra conceptual filosófica, pero tampoco la habilidad en la selección de los textos que cita y comenta, los rodeos por lo circunstancial de la época o de la vida de los personajes aludidos. Y diré más: siempre se cuela en sus escritos el clamor de la historia del momento en que escribe, porque no era un hombre enajenado sino profundamente comprometido con su tiempo. Un maestro de la lectura.

El relato intelectual que elabora Juan Carlos Rodríguez resulta siempre atractivo e incitante por variados motivos. No trataba tanto de que al final de su lectura el lector asumiera como suyas las ideas expuestas, sino ante todo, que compartiera las preguntas planteadas y se atreviera a elaborar sus propias respuestas. No es fácil descubrir la verdad ni tampoco decirla de manera eficaz como enseñó Bertolt Brecht, otra de las lecturas de cabecera de Juan Carlos Rodríguez. Hay que descubrirla y después encontrar la forma adecuada de transmitirla a los demás. Y en ello radican el mérito y también el compromiso del intelectual.

Pero vayamos a la parcela que he seleccionado, su manera de entender y explicar el drama burgués. Juan Carlos diferenció entre el teatro del primer capitalismo de los siglos XVI y XVII y el posterior. Para él

El teatro a partir del siglo XVI es así tanto ideología publica -ideología representada públicamente- como ideología de lo público: el teatro del XVI al XVIII no toca otro tema que el político en sentido amplio. Por una razón obvia: la escena pública será básicamente el «aparato» encargado de crear y tematizar los valores morales, los de conducta, existencia, etc., del nuevo espacio que ahora ha aparecido y que no tenía nombre. El espacio de la política o de la vida pública. ${ }^{\text {Io }}$

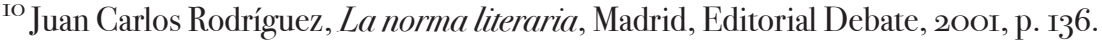


Con el triunfo del horizonte burgués a partir del siglo XVIII esto cambió, desapareciendo la política de la escena y surgiendo un teatro radicalmente diferente, que encontraba explicado por Diderot en su Paradoja del comediante, mejor que en nadie. El cambio no fue fácil, fue una batalla, que entre nosotros se manifiesta en hechos como la prohibición de los autos sacramentales, porque correspondían a una estructura pública sacralizada y si se trataba de desacralizar el Estado (al nivel político general), se tratará de desacralizar también la escena.

La nueva situación del teatro la explica desde una nueva noción: la noción de lo privado o de la privatización. Con el triunfo de las relaciones burguesas lo público va a ser concebido como una «transcripción directa» de los privado y esta es la base de las teorías de Diderot acerca del drama familiar y también de todas las teorías políticas que giran en torno a la idea del contrato social. El estado se concibe ahora solamente como una prolongación de los individuos que establecen el contrato. Y de aquí la profunda reestructuración social que ello conlleva. Diderot o Moratín se insertan en esta nueva manera de entender el teatro. Teorizan y practican la escena privada, el drama familiar, mientras que otros como Rousseau y sus seguidores niegan simplemente el teatro burgués tanteando otros caminos.

La escena debe ser para ellos la representación de la verdad privada una vez que esta se ha trasladado al plano de la representación. Se tratará en adelante que el espectador se identifique con la escena, creándose, gracias al desarrollo del escenario a la italiana, la ilusión escénica y la distancia que introduce entre el público y la representación. El escenario es un mundo aparte, aislado del espectador. Y es ahí donde comienzan las paradojas:

- la de la escenografía que sustituye al mundo real, pretendiéndose real ella misma.

- la del comediante, que debe luchar entre la identificación total con el personaje que representa y quien es él mismo; como es sabido, el asunto preocupó enormemente a Diderot, quien insistirá en que el actor debe establecer una distancia entre él y lo que representa, sometido a la construcción de la ilusión.

- la ilusión lograda en el escenario deberá atrapar al espectador, que se identificará con la escena; reirá o llorará con lo que suceda en ella. Por este lado se planteaba otro asunto de gran calado: la representación de las pasiones que constituyó todo un territorio nuevo de indagación.

Chocaban por tanto la aspiración de representar la realidad natural material y las nuevas ideas que sobre ella se tenían con el carácter modélico que se seguía otorgando al teatro y de aquí las paradojas a las que se enfrentaba Diderot en su reflexión. Diderot afirmaba que la escena debía estar llena únicamente de acontecimientos, personajes y oficios cotidianos y familiares, pero añadía a continuación que tales elementos familiares no debían representarse familiarmente - tal como ocurrían en la sala de estar de sus casassino que debían representarse modélicamente, esto es, extrayendo de la vida cotidiana sus normas, sus leyes generales y abstractas, su sentido último apenas visible. El drama tenía al cabo un fin didáctico. 
Entre pasionalidad y familiarismo por tanto discurrían las discusiones acerca del drama familiar llegando a situaciones paradójicas que Juan Carlos resumió en un párrafo que me gusta citar en mis cursos sobre el teatro ilustrado:

Digamos pues: la teoría escénica (artística) básica de Diderot se resuelve a partir de las siguientes categorías: $\mathrm{I}^{\mathrm{o}}$ ) el arte (el teatro) no «es» la vida; pero $2^{\circ}$ ) el arte (el teatro) debe ser un modelo de (y para) la vida cotidiana. Y en consecuencia $3^{\circ}$ ) ese modelo (ese «molde») tiene que ser extraído de la realidad cotidiana (la verdad natural) a la que la escena va dirigida, y no debe, por tanto, ser sólo producto de los «espectros» o de los «fantasmas» de un poeta más o menos «imaginativo».

Distancia e Ilusión se unifican así en este proyecto. Al ser el «arte» (la escena) modelo de «vida», ambos términos no pueden identificarse nunca entre sí. Aquél debe ser una superación (extractada, por decirlo así) de ésta; la vida concreta (la «naturaleza») constituye por su parte, la fuente directa del «arte» (de la escena), de la que hay que beber siempre para no producir fantasmagorías. ${ }^{\text {II }}$

Planteadas así las cosas, resulta evidente que el actor debe identificarse con su modelo de un modo completamente distinto a como el espectador se identifica con la escena. El actor debe escenificar según un modelo «mediador», diríamos de identificación; «nada pasa en al escena -indica Diderot-, exactamente como en la naturaleza», e incluso el mismo hecho de la declamación (su técnica) nos prueba ya que la representación no es natural; así el actor (...«copista riguroso de sí mismo o de sus sensaciones»...) no debe preferir el «instinto meramente natural al estudio ilimitado del arte», y ello en tanto que no es el hombre violento, que esta fuera de sí, el que nos posee, sino que éste es «un privilegio reservado al hombre que se domina a sí mismo». En otros términos: «la sensibilidad es la que prepara a los actores sublimes...» (mientras que la sensibilidad extrema conforma a los actores mediocres y la sensibilidad mediocre a la muchedumbre de malos actores). Pero a la vez esta práctica de la distancia (en cualquier sentido) es imprescindible para el logro de la ilusión identificadora. ${ }^{12}$

Hay un continuo bullir de paradojas en los textos reflexivos de Diderot pero todo puede resolverse a partir de una proposición básica:

todo escenario ha de basarse en la naturaleza, pero teniendo en cuenta que su funcionamiento, aunque teniendo que ser un modelo de «lo natural», no es exactamente igual que lo natural. Y lo mismo ocurre respecto al actor que, necesitan-

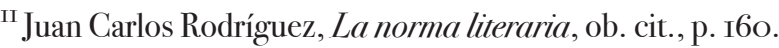

I2 Juan Carlos Rodríguez, La norma literaria, ob. cit., p. I6I.
} 
do inspirarse en la realidad cotidiana («naturalizada», diríamos en el léxico de la época) deberá sin embargo realizar una interpretación sublimadora y modélica, interpretación que permitirá a su vez que el espectador se identifique (se «reconozca» en lo representado. En una palabra, de igual modo que el Estado deberá ser reflejo (a la vez «modélico» $\mathrm{u}$ «liberal») de todos y cada uno de los ciudadanos que se han de identificar con él, así también es considerado el funcionamiento del teatro, esto es, como el lugar donde necesariamente se establece esa misma «distancia», ahora entre la escena y el público, para inmediatamente recuperarla mediante la ideología de la identificación. ${ }^{33}$

No he hecho hasta aquí sino exponer alguna de las cuestiones que trata Juan Carlos Rodríguez en este complejo ensayo teórico en los años setenta, cuando aquí se estaba casi apenas iniciando la ubicación correcta de la cultura ilustrada española. Siguen otros asuntos como su análisis Shakespeare y el que hizo Moratín hijo de Hamlet desde esta nueva perspectiva y que luego desarrollo en su edición citada.

Moratín, por un lado, suscribía las ideas diderotianas sobre el drama familiar, pero se encontró entre las manos con un texto excepcional como es Hamlet que las desbordaba y se empeñó en entender porqué sucedía que un texto que desbordaba esta poética, sin embargo, era un texto que lo fascinaba. Tradujo el drama, tratando de mantener el original sin alterarlo excesivamente y solo anotando a veces a pie de página su desacuerdo con el texto que traducía: determinadas escenas le parecían obscenas e iban contra el decoro ilustrado (la escena de los sepultureros; Hamlet echado en el regazo de Ofelia con juegos de palabras obscenas...). Quebraba Shakespeare el ideal de drama familiar, sin duda, pero a la vez era grandioso y no precisamente un bárbaro. ¿O sí?

Trató también de explicar el lenguaje del melodrama como una derivación del lenguaje pasional dieciochesco ligado a su sensibilidad. Analizó a grandes rasgos los avatares del drama familiar en manos de Moratín, pero introduciendo también a Sade, Artaud o Freud.

Moratín desplegaba, en efecto, hasta el extremo la temática del juego familiar, la familia en la sociedad burguesa, lejos ya de su carácter de linaje en la sociedad feudal. Se mostraba la familia en el lado más abierto de lo privado: en la sala de estar, en el salón donde se produce el contacto entre lo privado y lo público: El salón en la vivienda burguesa es el espacio donde la familia recibe. Pero nunca comparece el dormitorio, que es el verdadero núcleo de la privatización. Solamente Sade se atrevió a presentar ese espacio del dormitorio, el boudoir. Y por supuesto después Freud, hurgando en lo más íntimo y yendo hacia el inconsciente ideológico. O Artaud en Les Cenci (I935) rompiendo el esquema de la familia donde la parte superior y más elevada está representada por el padre. Él concibió su revolución teatral en buena parte como una revolución contra el padre. Es la imagen inversa de la familia presentada en sala de estar. Por el contrario, tomando un

\footnotetext{
I3 Juan Carlos Rodríguez, La norma literaria, ob. cit., p. I6I-I62.
} 
asunto de largo recorrido, pues ya había sido tratado por gentes como Shelley (The Cenci: A tragedy in five acts, Londres, I819), Stendhal en sus Crónicas italianas o Dumas en sus Crímenes célebres, aunque él trabajó sobre todo a partir del drama de Shelley, propuso una de sus ceremonias de crueldad donde quedan desvelados los comportamientos de un padre de familia que abusa de su poder, violentando a los suyos y hasta manteniendo relaciones incestuosas con su hija.

Moratín fue capaz de escribir algunos de los dramas familiares -al menos el $S i ́$ de las niñas - más consistentes de acuerdo con aquel modelo de drama, mostrando las relaciones familiares como un símbolo básico para mostrar aquel mundo. Son el eje del escenario: el amor y el dinero, o mejor, el primero sometido a este tienen una función fundamental.

Pero no hay que olvidar el reverso de la trama que saca a la escena Artaud o que sacará en cierto modo Brecht en obras como La boda de los pequeñoburgueses, mostrando las miserias del matrimonio en este nivel social.

Quiero apuntar un último aspecto del ensayo, para que se entienda el título. El estado actuará como árbitro a través de la censura cuando este modelo teatral vaya más lejos o por otro camino de la representación de lo privado. Es decir, el drama familiar confirma la familia burguesa y la proyección de esta como forma de estado. La confirma y la defiende de cuanto pueda perturbarla.

Es un ensayo, como se ve, lleno de sugerencias, de interrogantes que todo historiador del teatro español moderno no puede eludir leerlo. Ayudó lo suyo a leer correctamente y en profundidad el teatro de aquel periodo que, por otro lado, de la mano de historiadores como René Andioc, alcanzaba en su interpretación una gran precisión cuando se fue conociendo la realidad de los datos históricos y hasta estadísticos que subyacían en aquellas piezas. Mostraba los conflictos de la burguesía urbana española, colocándola en el salón de estar o en la sala de paso de una posada en El sí de las niñas con una gran agudeza.

El otro gran ensayo teatral de Juan Carlos Rodríguez es «Brecht y el poder de la literatura», que tuvo el acierto de dedicar a Ángeles Mora, su ángel guardián durante tantos años. Como decía, sus primeras claves venían de un ensayo de los setenta acerca de los Diarios de trabajo del dramaturgo alemán. Pero ahora Juan Carlos se esforzó en dar una visión de conjunto de su trayectoria arrancando de sus primeras y herméticas obras expresionistas - Baal, Tambores en la noche, En la jungla de las ciudades, Un hombre es un hombre- para ir a parar al final en sus dramas de madurez: Madre Coraje y sus hijos o Vida de Galileo Galilei.

El libro - ¿desde cuándo un prólogo tiene 2I4 densas páginas sin apenas notas?es por un lado un seguimiento de toda la trayectoria de Brecht y por otro, en cada una de las obras examinadas se dan unas claves para su comprensión tanto aislada como formando parte de todo el proceso creador brechtiano. Entre sus propuestas a primera vista sorprendentes hay dos, que son como cebos para el lector: 
- El teatro de Brecht nació para huir del aburrimiento y al menos esto hay que agradecérselo. Divertir, pero no al modo tradicional enajenador, sino concienciando.

- Y una segunda propuesta sería que a la vez que fue construyendo sus personajes fue construyendo su personaje sin saber muy bien quien quería ser en sus primeros pasos.

Solo con el paso del tiempo iría descubriendo Brecht la complejidad de lo real y desarrollando se peculiar manera de hacer teatro, dando cabida en la construcción de sus piezas a la historia y a la dialéctica; y fue así como además de las dos obras maestras citadas fue escribiendo y montando sus grandes piezas de madurez: Santa Juana de los mataderos, Arturo Ui, Puntilla y Mutti, El círculo de tiza caucasiano o El alma buena de Sezuán.

Construidas en largos procesos para encontrar la forma adecuada, lleno siempre de dudas. Consciente de la propia historicidad de cada representación: es decir, cómo decir de manera eficaz la verdad que se quiere transmitir en un momento y circunstancias dados. Nada que ver con lo que hacía años después el Berliner Ensemble con su mejor voluntad, pero representando un Brecht embalsamado. Pero este es otro asunto.

No le bastaba indudablemente la fórmula del drama familiar diderotiano y su aparente distancia entre la sala y la escena donde se produce la Ilusión de la realidad. Sabía que en ella los espectadores no están realmente distanciados de lo que sucede en la escena, porque hay un pacto previo por el que esos espectadores comparten inconsciente con quienes han configurado la escena. El público lleva en su interior lo que ocurre en la escena y esta lo confirma. Es lo sobreentendido, el instinto de clase que constituye la base de la propia individuación del público y los actores. Y es eso precisamente lo que intentará romper con su distanciamiento, lo que quiere poner en duda; y por eso quiere acabar con la falsa (por aparente) distancia del foso o de la cuarta pared estableciendo la distancia verdadera, rompiendo la ilusión teatral: o sea, las contradicciones que de hecho existen entre el inconsciente ideológico y su realización objetiva, sea en el teatro o sea en la vida.

Necesita este teatro un público distinto, dispuesto a reflexionar y a emprender un camino de cambio: el público de los explotados, que también está explotado inconscientemente, ideológicamente. Y es eso lo que hay que poner en cuestión haciéndole ver los engaños en que vive, las estrategias de ocultación que rigen los comportamientos capitalistas.

Su distanciamiento es un proceso a la individuación. Y al hacerlo rompe la aparente distancia diderotiana o burguesa, que buscaba precisamente de lo contrario: aceptar como algo natural la individuación burguesa a través del propio individuo, de la familia, del amor del dinero, etc. Lo hace especialmente en sus grandes dramas. Dice Juan Carlos,

la necesidad de Galileo de enfrentarse con la vieja era aristotélica es absolutamente similar a la necesidad brechtiana de transformar todo el viejo teatro burgués 
al que él también llama aristotélico. Por supuesto siempre con dudas. Sabe que tiene en las manos un núcleo básico, el de la explotación de clase. Pero sólo eso: como Galileo sólo tiene la seguridad de que la tierra gira alrededor del sol. El resto habrá que seguir investigándolo. ${ }^{\text {I4 }}$

Y en este punto aduce esta cita de Galileo en el drama homónimo, poniendo en su boca su propio proyecto:

Mi propósito no es demostrar que he tenido razón hasta ahora, sino saber si realmente la he tenido [...] Efectivamente lo pondremos en duda todo otra vez [...] Y sólo cuando hayamos fracasado, hayamos sido vencidos completa y desesperadamente y estemos lamiéndonos las heridas [...] comenzaremos a preguntarnos si no habremos tenido razón y es verdad que la tierra se mueve. Pero si cualquier otra hipótesis, salvo ésta, se nos deshace entre las manos, no tendremos piedad con los que no hayan investigado y sin embargo siguen hablando. ${ }^{5}$

Se trataba de proponer otra manera de ver, que tambalearía la historia, haciéndola cambiar de curso. Ese era el horizonte buscado.

No tenemos tiempo más que para ejemplificar sumariamente y copiando literalmente casi las palabras del crítico. En Madre Coraje y sus hijos el proceso en torno a la individuación llega al extremo. Se plantea si también tienen individuación los pobres. Sabemos el nombre propio de la cantinera, Anna Fierling, y su nombre de guerra: la Coraje. Esta mujer posee una individuación oblicua, que surge de la imagen invertida del hombre, Coraje (que ha tenido al menos tres hombres y un hijo con cada uno de ellos), en realidad solamente es individualizada por la guerra ${ }^{16}$.

La guerra de referencia es la de los Treinta años que asoló la mitad del siglo XVII europeo. Disfrazada como guerra de religión entre el Imperio católico y los protestantes, en realidad fue una masacre que limó todos los aspectos sociales de la Reforma y apuntaló el capitalismo. Guerra y larga y dura del primer capitalismo para imponerse al viejo sistema feudal. Parábola a su manera de la Segunda Guerra Mundial que se veía venir en I939. Brecht intentó mostrar su desprecio de la vida por la guerra y hacia la vida como guerra, mostrando la cotidianización de la guerra.

Para Juan Carlos no es un alegato sobre la guerra en abstracto sino sobre sus efectos cotidianos concretos, ciñéndose no tanto al propio espacio bélico, sino a sus márgenes o límites. Y esos límites son muy precisos: la cantinera y sus hijos, el predicador, el cocinero y la prostituta. Y por supuesto el carro mismo de Madre Coraje metáfora de esa degradación creciente, que Brecht graduó perfectamente haciendo que se degradara a medida que avanzaba el drama.

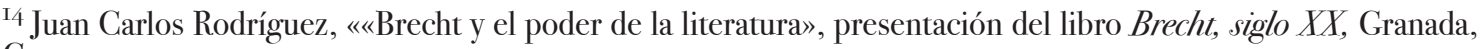
Comares, I999, p. I95.

I5 Ibidem.

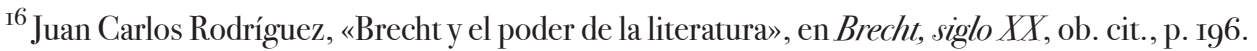


La situación es cruel. ¿Pueden hacer negocio los de abajo con la guerra? Coraje así lo ve en las primeras seis escenas hasta que en esta -como en un paréntesis según Brecht- lo ve de otro modo.

La guerra es enfocada desde el punto de vista de los pobres, desde la explotación. Entra a analizar lo familiar en el drama brechtiano, pues una familia es. Esta mujer produce hijos y es mantenedora por tanto de la fuerza de trabajo; tres tiene y los tres irán muriendo según avance la obra. No tiene marido y es negociante: entra en el negocio de la guerra, porque ha descubierto el mercado y que este se supone que da una individualidad como persona e incluso como familia. Coraje pretende mantener a sus hijos poniendo su carro a disposición de la guerra, peor la guerra le irá arrebatando a sus hijos y al final se verá sola con su carro destruido. Tres muertes jalonan el proceso de degradación:

I. Eiffel. El primer hijo es reclutado, prometiéndole la gloria y el dinero. Mata a unos campesinos robándoles su ganado. Esto le hace un héroe y como tal es festejado. Con ese ganado come el ejército y Coraje hace negocio vendiendo un ganso para la celebración. El negocio y la familia prosperan gracias a la guerra, cree entonces Coraje.

Pero pasados unos años, unas escenas, será juzgado y condenado a muerte por lo mismo que lo hizo un héroe. Matar campesinos y robarles el ganado, la precaria paz le ha convertido de héroe en asesino.

2. El segundo hijo, el «queso suizo» como lo llama Coraje, es contador de un regimiento protestante. Cuando llegan los católicos, esconde la caja, pero un tuerto lo delata. Coraje vuelve a creer en el negocio. Como solo el dinero ablanda a los hombres, discute por el precio de su libertad: el tuerto y otros espías exigen 200 florines. Coraje está dispuesta a darlos pero no sin regatear antes. Pero cuando acaba su regateo ya es tarde: suenan los tambores que anuncian su fusilamiento.

3. Su hija Kattrin, la chica muda, también la perderá. En su silencio es acaso el personaje más grandioso. Quedó muda de niña por unos trapos que le metieron unos soldados al violarla.

Aún así le gustaría hacer el amor por gusto, ama los niños, etc. Cuida a los heridos. Es solidaria. Fue mutilado su rostro en una confrontación con lo que queda fuera del mercado matrimonial. Nada le sale bien. Ilusionada Coraje con un cocinero, este impone que cuando se vayan a regentar una posada, la muchacha no irá con ellos... Pero aún tiene el rasgo heroico de salvar la ciudad con el tambor y de morir de un arcabuzazo.

Coraje la encuentra muerta y solo acierta a cantarle una nana como si estuviera dormida. Y ya sola se ve obligada a engancharse a su carro y seguir. Mal acabó su negocio. Sin hijos y arruinada. El negocio de la guerra no es para los de abajo, sino para quienes manejan ocultos sus hilos. Los de abajo tienen que tener coraje hasta para reproducirse, porque solo reproducen miseria y hambre.

Brecht y con él Juan Carlos se pregunta: ¿Cuándo se romperá el silencio de los de abajo precisamente para salvar la vida?

Es la pregunta que queda en el aire en este impresionante drama, que él destripa, ahondando más allá de lo anecdótico, mostrando esa condición falseada de la mujer, 
explotada, no solo Coraje o su hija, también la prostituta Yvette (otra forma de aparente negocio).

Las contradicciones del drama familiar son puestas así al descubierto, llevadas a su límite y limitaciones en la sociedad capitalista, que late y negocia por detrás. Que suma millones de muertos sin pudor si puede sumar beneficios económicos millonarios. Nada importa el individuo desolado, sometido a una total explotación y más todavía si es mujer.

Hasta aquí apenas un breve y apresurado resumen del análisis del drama realizado por Juan Carlos, como siempre trascendiendo la anécdota y yendo a los conflictos ideológicos de fondo. Como siempre, maestro de la lectura.

Quiero concluir -si me permiten cinco minutos más, quizás menos- con un breve juego de espejos. En De qué hablamos cuando hablamos de marxismo (2013) recoge Juan Carlos su ensayo «Althusser: Bow-up (las líneas maestras de un pensamiento distinto)» donde explica lo que significó para él este maestro a la vez que expone sus grandes ideas y también las fisuras de su pensamiento. Todo el ensayo discurre sobre el filo de la navaja de la discusión argumentada de sus coincidencias y sus diferencias, movida por el deseo de reivindicar su verdadero legado intelectual, desarrollado entre tantas dificultades y al final emborronado por la locura. Es de una calidad excepcional el montaje de sus secuencias, pero único en su última página «Final y fundido en negro: la calle donde nunca daba el sol», que rememora sus últimos encuentros con Althusser. En medio de los ataques y rodeado el maestro de signos «de desolación, de exilio, de derrota», encontraron la forma de sonreír y hasta de reír a carcajadas. Qué sería del ser humano rodeado de miserias si no tuviera capacidad para reír.

La soledad y el vacío cercan con frecuencia al intelectual moderno cuando no se aviene a la militancia fácil de un partido político, aunque este enarbole la bandera del compromiso. Una frase de Althusser resume a la perfección la coyuntura en que se han encontrado a lo largo del siglo XX quienes optaron por el marxismo como método de análisis de la realidad: "Yo era militante comunista y quería saber lo que era el marxismo.» Con esta rotunda frase resumía las muchas dificultades que encontraron dentro del propio Partido Comunista Francés muchas de sus propuestas. Valdría extrapolarlo a lo acontecido entre nosotros con propuestas como las de Juan Carlos Rodríguez, porque forma parte de quienes creemos que la filosofía debe ser guardiana de la política y no al revés. Comunismo y marxismo han andado cada uno por su lado y han sido los partidos comunistas los primeros que han tergiversado el marxismo hasta lo imposible.

Quienes piensan que el marxismo es algo pasado no han entendido nada de nada. El marxismo planteó una ciencia nueva, el materialismo histórico, que no es otra cosa que la ciencia de la historia. Y es ahí donde muestra su vigencia: tratando de explicar la explotación del hombre por el hombre, contribuyendo a crear unas subjetividades diferentes no diseñadas para explotar a los otros. En esto consiste pensar desde la explotación.

El título del ultimo libro de Juan Carlos - Para una teoría de la literatura- me ha traído a la mente estos días mientras redactaba estas notas - deben ser cosas de mi «in- 
consciente ideológico»- una canción de Joan Manuel Serrat de las mismas fechas en que Juan Carlos Rodríguez elaboró y defendió su tesis a comienzos de los años setenta: «Para la libertad». Como es sabido es el comienzo de un verso de la segunda parte del poema «El herido», perteneciente al libro de Miguel Hernández El hombre acecha (I937-I838) cuyas estrofas convirtió Serrat en canción para su álbum Miguel Hernández (1972). Su presentación de la lucha por la libertad como una pasión irrenunciable lo convirtió en un verdadero himno para los luchadores por la libertad en los últimos años del franquismo, luego durante la transición y así hasta hoy. Nos ha acompañado durante estos mismos cuarenta años.

Al final resulta que la intencionalidad del poeta, la del cantante y la del historiador de la literatura comprometidos no han sido muy diferentes. Con su «inconsciente ideológico» a cuestas, como cada cual, pero con el horizonte claro y caminando decididos hacia él. La clave reside en el para qué de sus luchas: para la libertad sin explotación. De esto hablaba Juan Carlos Rodríguez cuando hablaba de literatura, afanándose durante años en la construcción de su teoría de la literatura.

Y acabo. Es para mi muy grato comprobar esta mañana granadina de otoño recién estrenado, que Juan Carlos no forma parte de los Olvidos de Granada, -por volver a Juan Ramón y a aquella inolvidable revista, que trató de rescatar olvidos culturales de esta ciudad-sino que se le homenajea como MAESTRO Y AMIGO, los dos mejores títulos que honran a un hombre en el buen sentido de la palabra bueno. 